\title{
Infrared spectrum and UV-induced photochemistry of matrix-isolated 5-methoxy-1-phenyl-1H-tetrazole
}

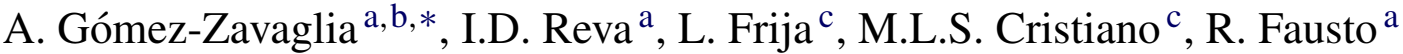 \\ ${ }^{a}$ Department of Chemistry, University of Coimbra, Portugal \\ ${ }^{\mathrm{b}}$ Facultad de Farmacia y Bioquímica, Universidad de Buenos Aires, Argentina \\ ${ }^{c}$ Department of Chemistry and Biochemistry, University of Algarve, Faro, Portugal
}

Received 19 September 2005; received in revised form 17 October 2005; accepted 18 October 2005

Available online 5 December 2005

\begin{abstract}
The molecular structure, vibrational spectra and photochemistry of 5-methoxy-1-phenyl- $1 H$-tetrazole (5MPT) were studied by matrix isolation infrared spectroscopy and DFT(B3LYP)/6-311++G(d,p) calculations. According to the calculations, only one double degenerated-by-symmetry minimum exists in the ground state PES of the compound. In this structure, the dihedral angle between the two rings (phenyl and tetrazole) is ca. $30^{\circ}$, whereas the methoxyl group stays nearly in the plane of the tetrazole ring. In consonance with the theoretical predictions, only one molecular species was experimentally observed in the as-deposited argon matrices. Theoretical calculations were also used to help in assignment of the experimental spectrum of the compound, the calculated spectrum showing a very good agreement with the experimental data. In situ UVirradiation $(\lambda>235 \mathrm{~nm})$ of the matrix-isolated 5MPT induced unimolecular decomposition of the compound, which led mainly to production of methylcyanate and phenylazide, this latter further reacting to yield, as final product, 1-aza-1,2,4,6-cycloheptatetraene. 3-Methoxy-1-phenyl-1Hdiazirene was also observed experimentally as minor product, resulting from direct elimination of molecular nitrogen from $5 \mathrm{MPT}$.
\end{abstract}

(C) 2005 Elsevier B.V. All rights reserved.

Keywords: 5-Methoxy-1-phenyl-1H-tetrazole; 3-Methoxy-1-phenyl-1H-diazirene; Phenylazide; 1-Aza-1,2,4,6-cycloheptatetraene; Methylcyanate; Tetrazole ring cleavage; Matrix isolation IR spectroscopy; DFT(B3LYP)/6-311++G(d,p) calculations

\section{Introduction}

The practical relevance of tetrazole-based compounds in fields such as agriculture (as pesticides) and medicine (as antihypertensive, antiallergic, antibiotic and anticonvulsant agents as well as in cancer and AIDS treatments) is well known [1-9]. Indeed, the extensive applications of tetrazoles stimulated research in areas such as the design of synthetic methodologies and the reactivity of various tetrazolyl derivatives. Among these are 5-alkoxy- and 5-aryloxy-1-aryl tetrazoles. Efficient and easy to carry synthetic methodologies to these compounds have been described [10,11]. 5-Alkoxy-1-aryl tetrazoles are also very important compounds from a synthetic view point because they act as intermediates to the preparation of 5-alkyl-1-aryl-4,5dihydro- $1 H$-tetrazol-5-ones via a thermally induced Chapmann isomerization $[12,13]$.

\footnotetext{
* Corresponding author. Tel.: +351 239854 483; fax: +351 239827703 .

E-mail address: angoza@qui.uc.pt (A. Gómez-Zavaglia).
}

In spite of that, very little attention has been given in the past to the study of this family of compounds at a molecular level. Recently, a research program aiming to fill this gap was started in our laboratories. Unsubstituted tetrazole [14] and some of its representative derivatives were already studied under this program, including 1-phenyltetrazole [15], 5chlorotetrazole [16], 5-chloro-1-phenyltetrazole [15], 2-methyl$2 \mathrm{H}$-tetrazol-5-amine [17], 5-mercapto-1-methyltetrazole [18] and 1-phenyltetrazolone [19]. In these studies, the molecular structure, tautomerism, vibrational spectra and photochemistry of tetrazoles were investigated by a concerted approach using matrix isolation infrared spectroscopy and high-level DFT-based theoretical calculations.

Regarding their photochemistry, tetrazoles have been found to be extremely interesting and challenging molecules. Most of times, several UV-induced processes occur simultaneously and the relative importance of each one has been shown to be strongly dependent on the substituents of the tetrazole ring [17-23]. In general, the presence of photochemically labile hydrogen atoms (either directly linked to the tetrazole ring or belonging to the 
tetrazole substituents) has been found to be a source of complexity, opening additional reaction channels or allowing secondary photochemical reactions to take place concomitantly with the main primary photoprocesses [19-23]. This behavior is also exhibited by matrix-isolated compounds, where essentially unimolecular reactions can occur due to the cage-confined nature of the processes occurring in these media (in the matrices, molecular diffusion is inhibited except when very small species are produced).

In the present study, 5-methoxy-1-phenyl- $1 \mathrm{H}$-tetrazole (5MPT) was elected as subject of analysis. The choice of this compound was based on two criteria required for having a relatively simple photochemistry: it has only one stable conformation and does not have labile hydrogen atoms directly bound to the tetrazole ring or in the tetrazole substituents. This way, the photochemistry of 5MPT could be expected to be simpler than those observed for previously studied tetrazoles [19-23] and its study appeared potentially useful for allowing improvement of the knowledge on the photochemistry of this type of compounds.

\section{Materials and methods}

\subsection{Infrared spectroscopy}

5MPT was synthesized as described elsewhere [24,25]. The IR spectra were obtained using a Mattson (Infinity 60AR Series) Fourier transform infrared spectrometer, equipped with a deuterated triglycine sulphate (DTGS) detector and a $\mathrm{Ge} / \mathrm{KBr}$ beamsplitter, with $0.5 \mathrm{~cm}^{-1}$ spectral resolution. In order to avoid interference from atmospheric $\mathrm{H}_{2} \mathrm{O}$ and $\mathrm{CO}_{2}$, a stream of dry nitrogen continuously purged the optical path of the spectrometer. The compound was placed in a specially designed doubly thermostattable Knudsen cell [26], whose compartments (sample container and valve nozzle) were kept at $323 \mathrm{~K}$ during deposition of the matrix. Matrices were prepared by co-deposition of 5MPT vapors coming out of the Knudsen cell together with large excess of the matrix gas (argon N60, obtained from Air Liquide) onto the CsI substrate of the cryostat cooled to $9 \mathrm{~K}$. The obtained matrices did not present any evidence of presence of associates of the deposited compound. All experiments were performed using an APD Cryogenics closed-cycle helium refrigeration system with a DE-202A expander.

Irradiation of the samples was carried out with a $150 \mathrm{~W}$ xenon arc lamp (Osram XBO 150W/CR OFR), through the outer $\mathrm{KBr}$ window of the cryostat $(\lambda>235 \mathrm{~nm})$.

\subsection{Computational methodology}

The quantum chemical calculations were performed with Gaussian98 [27] at the DFT level, using the 6-311++G(d,p) basis set and the B3LYP density functional $[28,29]$. Geometrical parameters were optimized using the Geometry Direct Inversion of the Invariant Subspace (GDIIS) method [30]. In order to assist the analysis of the experimental spectra, vibrational frequencies and IR intensities were also calculated with the same basis set. The computed harmonic frequencies were scaled down by a single factor (0.978) to correct them mainly for the effects of basis set limitations, neglected part of electron correlation and anharmonicity effects. Normal coordinate analysis was undertaken in the internal coordinates space, as described by Schachtschneider [31], using the program BALGA and the optimized geometries and harmonic force constants resulting from the DFT(B3LYP)/6-311++G(d,p) calculations.

\section{Results and discussion}

\subsection{Molecular geometry}

The optimized geometry of 5MPT, obtained at the DFT(B3LYP)/6-311++G(d,p) level of calculation, is provided in Table S1 (Supplementary Information) and shown graphically in Fig. 1. 5-methoxy-1-phenyl-1H-tetrazole has two rotational axes $\left(-\mathrm{C}_{6}-\mathrm{N}_{1}-\right.$ and $\left.-\mathrm{O}-\mathrm{CH}_{3}\right)$ that could in principle give rise to different conformers. However, only one minimum (doubly degenerated by symmetry) was located in the potential energy surface of the molecule. In the minimum energy structure, the molecule adopts a geometry in which the methyl group is as far as possible from the phenyl group $\left(\mathrm{N}_{1}-\mathrm{C}_{5}-\mathrm{O}_{17}-\mathrm{C}_{18}\right.$ dihedral angle $\sim 180^{\circ}$ ) and the inter-ring twisting angle is ca. $30^{\circ}$.

The inter-ring angle is determined by the balance between three main factors: (i) conjugation of the $\pi$ electron systems of both rings, which favors their coplanarity; (ii) steric repulsion between the substituents on the tetrazole ring, which favors a non-planar geometry; and (iii) intramolecular H-bond-like interaction between the ortho-hydrogen atoms of the phenyl ring and $\mathrm{O}_{17}$ or $\mathrm{N}_{2}$ atoms $\left(\mathrm{H}_{12} \cdots \mathrm{N}_{2}\right.$ and $\mathrm{H}_{16} \cdots \mathrm{O}_{17}$ interactions can be expected to favor non-coplanar and coplanar arrangements of the two rings, respectively). In view of the accumulated data on several molecules with two rings connected by a single bond (e.g., 2-phenylpyridine, 2phenylimidazole, 1-methyl-2-phenylimidazole, 4,6-dichloro-2methylthio-5-phenylpyrimidine and several phenyl-substituted members of the tetrazole family [15,32-43]), among those three effects, the second appears to be the dominant one. Indeed, it has been demonstrated that the size of the sterically interacting

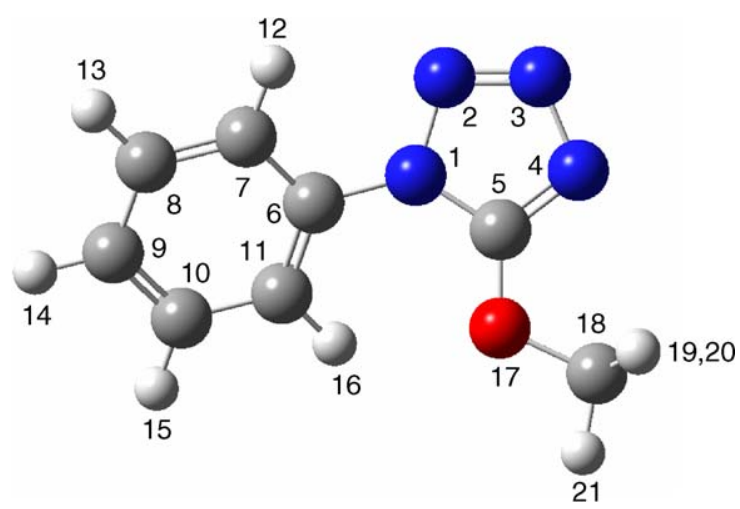

Fig. 1. B3LYP/6-311++G(d,p) optimized geometry of 5-methoxy-1-phenyl-1Htetrazole with atom numbering. Calculated energy (with zero point vibrational correction) and dipole moment are $-1585361.34 \mathrm{~kJ} \mathrm{~mol}^{-1}$ and $5.2 \mathrm{D}$. The $\mathrm{C}_{7} \mathrm{C}_{6} \mathrm{~N}_{1} \mathrm{C}_{5}$ and $\mathrm{N}_{1} \mathrm{C}_{5} \mathrm{O}_{17} \mathrm{C}_{18}$ dihedral angles are predicted as being $151.3^{\circ}$ and $-177.0^{\circ}$, respectively. 
substituents in the two rings is determinant on the relative orientation of the rings [15,32-43]. This effect is clearly observed, for example, when comparing 5-chloro-1-phenyltetrazole [15] with 5MPT. 5-Chloro-1-phenyltetrazole has larger interacting substituents and displays a larger inter-ring twisting angle $\left(54.2^{\circ}\right.$ versus $28.7^{\circ}$ in 5MPT, at the DFT(B3LYP)/6-311++G(d,p) level of theory). On the other hand, the inter-ring dihedral angle in 1-phenyltetrazole was found to be $12.8^{\circ}$ in the crystalline

Table 1

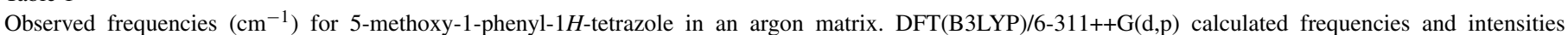
$\left(\mathrm{km} \mathrm{mol}^{-1}\right)$ are given for comparison ${ }^{\mathrm{a}}$

\begin{tabular}{|c|c|c|c|c|}
\hline Approximate description & Calculated frequency & Calculated intensity & Observed frequency $\operatorname{Ar}(9 \mathrm{~K})$ & $I$ \\
\hline$v(\mathrm{C}-\mathrm{H}$ P-ring 1$)$ & 3148.5 & 0.7 & 3117.0 & w \\
\hline$v(\mathrm{C}-\mathrm{H}$ P-ring 2$)$ & 3144.9 & 0.3 & n.o. & \\
\hline$v(\mathrm{C}-\mathrm{H}$ P-ring 3$)$ & 3123.0 & 14.8 & 3094.6 & $\mathrm{w}$ \\
\hline$v(\mathrm{C}-\mathrm{H}$ P-ring 4$)$ & 3111.7 & 10.9 & 3082.4 & $\mathrm{w}$ \\
\hline$v(\mathrm{C}-\mathrm{H}$ P-ring 5$)$ & 3101.5 & 0.0 & n.o. & \\
\hline$v \mathrm{CH}_{3}$ as.' & 3096.5 & 9.3 & 3072.2 & $\mathrm{w}$ \\
\hline$\nu \mathrm{CH}_{3}$ as." & 3064.8 & 12.2 & 3045.8 & $\mathrm{w}$ \\
\hline $2 \times \delta(\mathrm{C}-\mathrm{H}$ ring 2$)$ & & & 3012.8 & $\mathrm{w}$ \\
\hline$v \mathrm{~N}=\mathrm{C}+\nu \mathrm{C}-\mathrm{N}$ & & & 2997.7 & $\mathrm{w}$ \\
\hline$\nu \mathrm{CH}_{3} \mathrm{~s}$ & 2988.1 & 36.1 & 2958.8 & $\mathrm{~m}$ \\
\hline$v(\mathrm{C}-\mathrm{C}$ P-ring 2) & 1605.4 & 24.4 & 1604.6 & $\mathrm{~m}$ \\
\hline$v(\mathrm{C}-\mathrm{C}$ P-ring 4$)$ & 1598.7 & 38.8 & 1600.5 & $\mathrm{~m}$ \\
\hline$v \mathrm{~N}=\mathrm{C}$ & 1562.4 & 259.5 & $1572.3 / 1571.3$ & $\mathrm{~S} / \mathrm{sh}$ \\
\hline$\nu(\mathrm{C}-\mathrm{C}$ P-ring 1$)+\gamma \mathrm{NC}$ & & & 1539.2 & w \\
\hline$\delta(\mathrm{C}-\mathrm{H}$ P-ring 2$)$ & 1499.6 & 121.5 & $1512.5 / 1510.5$ & $\mathrm{~S} / \mathrm{sh}$ \\
\hline$\gamma(\mathrm{C}-\mathrm{H}$ P-ring 1$)+\nu \mathrm{C}-\mathrm{O}$ & & & 1488.5 & w \\
\hline$\delta \mathrm{CH}_{3} \mathrm{as}^{\prime}$ & 1466.8 & 19.4 & 1469.6 & $\mathrm{~m}$ \\
\hline$\delta(\mathrm{C}-\mathrm{H}$ P-ring 3$)$ & 1458.0 & 7.5 & 1462.5 & $\mathrm{w}$ \\
\hline$\delta \mathrm{CH}_{3}$ as." & 1450.0 & 10.9 & 1456.3 & $\mathrm{~m}$ \\
\hline$v \mathrm{C}-\mathrm{N}$ & 1442.1 & 108.4 & $1450.1 / 1448.0$ & $\mathrm{~m} / \mathrm{m}$ \\
\hline$\delta \mathrm{CH}_{3} \mathrm{~s}$ & 1424.3 & 70.9 & $1426.1 / 1424.8$ & $\mathrm{sh} / \mathrm{m}$ \\
\hline $2 \times \tau($ T-ring 1$)$ & & & 1345.6 & w \\
\hline$v \mathrm{~N}=\mathrm{N}$ & 1342.4 & 32.4 & 1335.4 & w \\
\hline$\delta(\mathrm{C}-\mathrm{H}$ P-ring 1$)$ & 1326.1 & 3.4 & 1320.5 & $\mathrm{w}$ \\
\hline$v(\mathrm{C}-\mathrm{C}$ P-ring 3$)$ & 1299.7 & 5.8 & 1307.1 & w \\
\hline$v \mathrm{~N}-\mathrm{C}[\mathrm{FR}$ with $\delta($ T-ring 1$)+\delta(\mathrm{P}$-ring 2$)]$ & 1289.2 & 23.4 & $1300.2 / 1298.7 / 1286.2 / 1284.0$ & $\mathrm{w} / \mathrm{sh} / \mathrm{w} / \mathrm{sh}$ \\
\hline $2 \times \delta(\mathrm{P}$-ring 2$)$ & & & 1248.1 & $\mathrm{w}$ \\
\hline$\gamma \mathrm{CH}_{3}^{\prime}$ & 1187.2 & 13.1 & 1195.1 & $\mathrm{~m}$ \\
\hline$\delta(\mathrm{C}-\mathrm{H}$ P-ring 4$)$ & 1177.2 & 1.2 & 1182.1 & $\mathrm{w}$ \\
\hline$\delta(\mathrm{C}-\mathrm{H}$ P-ring 5$)$ & 1158.7 & 0.2 & 1169.1 & w \\
\hline$\gamma \mathrm{CH}_{3}^{\prime \prime}$ & 1148.6 & 0.7 & 1161.6 & $\mathrm{w}$ \\
\hline$\nu \mathrm{N}-\mathrm{N}$ & 1111.3 & 41.3 & 1122.7 & $\mathrm{~m}$ \\
\hline$\delta($ T-ring 2$)$ & 1091.5 & 16.1 & $1101.3 / 1096.9$ & $\mathrm{w} / \mathrm{w}$ \\
\hline$\nu(\mathrm{C}-\mathrm{C}$ P-ring 6) $[\mathrm{FR}$ with $\delta \mathrm{NC}+\gamma \mathrm{NC}]$ & 1065.7 & 84.0 & 1090.4/1087.5/1072.9/1070.9 & $\mathrm{w} / \mathrm{sh} / \mathrm{sh} / \mathrm{m}$ \\
\hline$v(\mathrm{C}-\mathrm{C}$ P-ring 5$)$ & 1041.6 & 10.0 & 1046.8 & W \\
\hline$v(\mathrm{C}-\mathrm{C}$ P-ring 1$)$ & 1015.6 & 18.5 & 1024.1 & $\mathrm{~m}$ \\
\hline$\nu \mathrm{O}-\mathrm{C}[\mathrm{FR}$ with $2 \times \gamma \mathrm{NC}]$ & 1001.5 & 42.1 & 1014.2/1011.5 & $\mathrm{m} / \mathrm{m}$ \\
\hline$\delta($ P-ring 1$)$ & 994.8 & 0.3 & n.o. & \\
\hline$\gamma(\mathrm{C}-\mathrm{H}$ P-ring 5) & 979.3 & 0.1 & n.o. & \\
\hline$\tau(\mathrm{P}$-ring 3$)$ & 965.0 & 2.4 & 985.2 & $\mathrm{w}$ \\
\hline$v \mathrm{~N}-\mathrm{N}^{\prime}$ & 963.1 & 14.6 & $969.9 / 967.2$ & $\mathrm{~m} / \mathrm{m}$ \\
\hline$\gamma(\mathrm{C}-\mathrm{H}$ P-ring 3$)$ & 909.5 & 4.4 & $910.6 / 909.2$ & w/sh \\
\hline$\gamma(\mathrm{C}-\mathrm{H}$ P-ring 2$)$ & 830.3 & 0.1 & n.o. & \\
\hline$\gamma(\mathrm{C}-\mathrm{H}$ P-ring 1$)[\mathrm{FR}$ with $2 \times \gamma \mathrm{CO}]$ & 753.4 & 57.8 & $758.5 / 756.5 / 754.9$ & $\mathrm{~m} / \mathrm{m} / \mathrm{m}$ \\
\hline$v \mathrm{C}-\mathrm{O}$ & 736.2 & 4.1 & 745.7 & w \\
\hline$\tau$ (T-ring 2) & 717.7 & 5.1 & $733.5 / 727.9$ & $\mathrm{w}$ \\
\hline$\tau$ (T-ring 1) & 689.3 & 12.4 & $697.5 / 695.0$ & w/w \\
\hline$\tau(\mathrm{P}$-ring 1$)[\mathrm{FR}$ with $2 \times \delta(\mathrm{P}$-ring 3$)]$ & 679.4 & 14.8 & $685.9 / 684.0$ & $\mathrm{w} / \mathrm{w}$ \\
\hline$\delta($ T-ring 1$)$ & 670.4 & 17.9 & 674.0 & $\mathrm{w}$ \\
\hline$\delta(\mathrm{P}$-ring 2$)$ & 616.5 & 0.2 & 623.7 & $\mathrm{w}$ \\
\hline$\delta \mathrm{NC}$ & 576.2 & 3.9 & 583.0 & $\mathrm{w}$ \\
\hline$\gamma \mathrm{NC}$ & 499.6 & 12.2 & 505.6 & $\mathrm{w}$ \\
\hline$\gamma(\mathrm{C}-\mathrm{H}$ P-ring 4$)$ & 405.5 & 0.2 & n.o. & \\
\hline
\end{tabular}

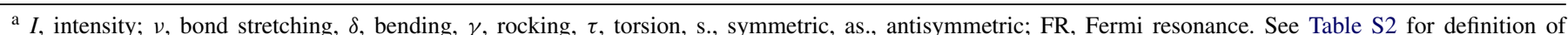

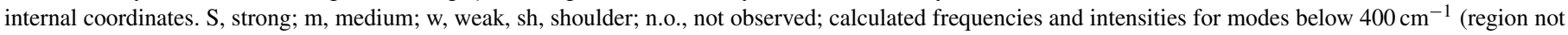
experimentally investigated) are given in Table S3.T-ring, tetrazole ring; P-ring, phenyl ring. 
phase [40], i.e. smaller than in both 5MPT and 5-chloro-1phenyltetrazole.

Note that the effect of the intramolecular H-bond-like interactions between the ortho-hydrogen atoms of the phenyl ring and $\mathrm{O}$ or $\mathrm{N}$ atoms was found to be relevant in 1-phenyltetrazolone, where both interactions tend to favor the coplanarity between the two rings [19]. In that molecule, the two rings were indeed found to be coplanar (inter-ring twisting angle: $0^{\circ} ; \mathrm{H}_{16} \cdots \mathrm{O}_{17}$ distance: $225.9 \mathrm{pm}$ [19]). On the other hand, in both 1-phenyltetrazolone and 5MPT conjugation of the $\pi$ electron systems of phenyl and tetrazole rings does not seem to be very important, considering the estimated values for the $\mathrm{C}-\mathrm{N}$ inter-ring distance (142.6 and $142.4 \mathrm{pm}$, respectively), which can be compared with those found for alkylamines (essentially pure $\mathrm{C}-\mathrm{N}$ single bond: within the 145-147 pm range [44]) and, for instance, methylenimine $\left(\mathrm{H}_{2} \mathrm{C}=\mathrm{NH}\right.$, double bond: $127.3 \mathrm{pm}$ [45] $)$. In simple diazines (pyrazine, pyrimidine and pyridazine), where the $\mathrm{CN}$ bond lengths have a bond order of ca. $1.5 \mathrm{pm}$ - conjugated system - the bond lengths are ca. $133.5 \mathrm{pm}$ [46-48], i.e., considerably shorter than the $\mathrm{C}-\mathrm{N}$ inter-ring distance in 5MPT.

\subsection{IR spectrum of the matrix-isolated compound (as-deposited matrix)}

5MPT minimum energy structure belongs to the $C_{1}$ symmetry point group. It has 57 fundamental vibrations, all predicted to be active in the infrared. Fig. 2 displays the spectrum of the asdeposited compound (nozzle temperature: $323 \mathrm{~K}$ ). The matrix- isolated monomer of 5MPT gives rise to an IR spectrum that fits nicely the calculated spectrum [DFT(B3LYP)/6-311++G(d,p)], which is also shown in Fig. 2, for comparison. Table 1 presents the proposed band-assignments. The definition of the internal coordinates used in this study to perform the normal coordinates analysis is given in Table S2 (Supplementary Information), while Table S3 (Supplementary Information) shows the full details of the calculated spectra, including normal mode characterization in terms of the potential energy distribution (PED).

In practical terms, the IR spectrum of 5MPT can be considered as being basically constituted by two groups of bands: one associated with the vibrational modes of the phenyl group and the other with the tetrazole ring.

The bands corresponding to the first group show very slight differences among different 1-phenyltetrazole compounds, appearing at nearly the same frequencies as in 1-phenyltetrazole [15], 5-chloro-1-phenyltetrazole [15] and 1-phenyltetrazolone [19], for example. This means that a second substituent on the tetrazole ring does not have a strong influence on the phenyl group, a result that is also in consonance with a small conjugation of the $\pi$ electron systems of phenyl and tetrazole rings in 5MPT (also in agreement with these results is the fact that the optimized structures of the various 1-phenyltetrazole compounds already studied $[15,19]$ do not show any substantial differences in the geometry of the phenyl group).

Contrary to what succeeds for the phenyl vibrations, as it could be expected, the tetrazole ring vibrations are strongly affected by the substituent in the 5-position and differ considerably among different compounds.
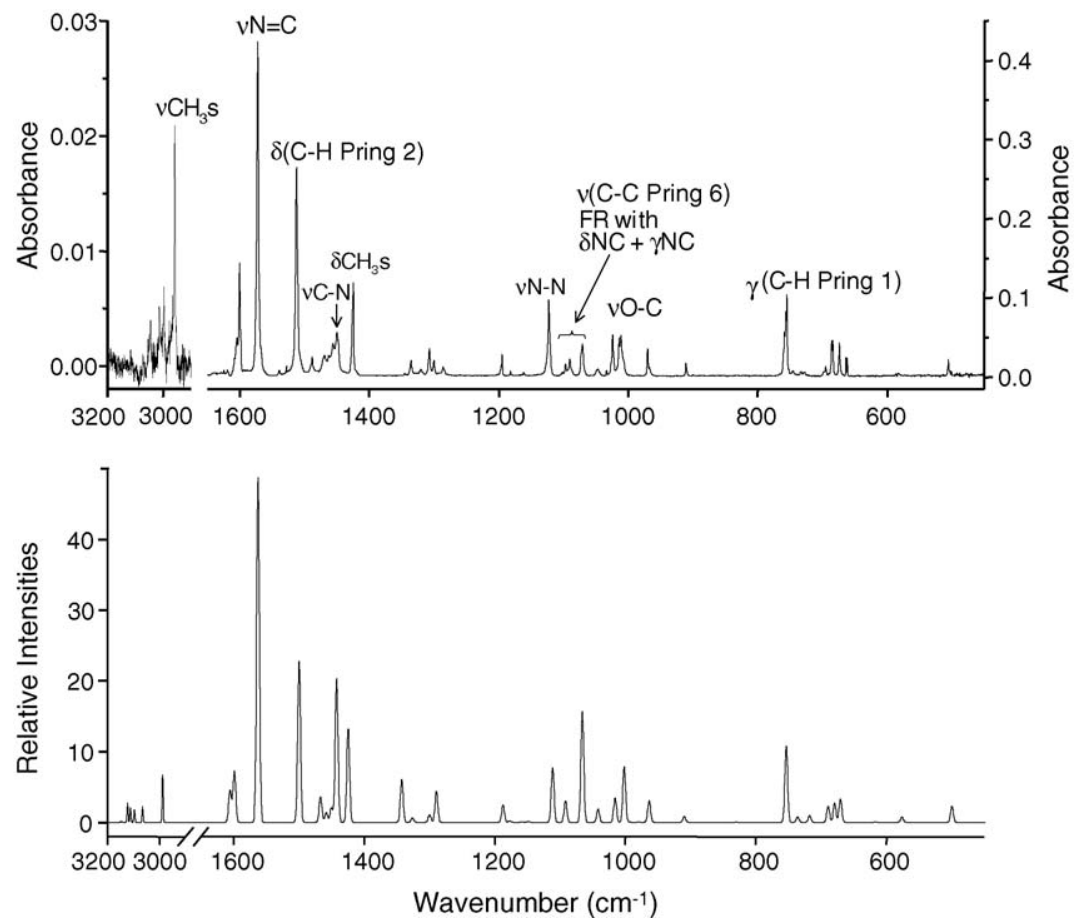

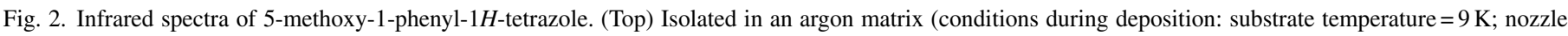

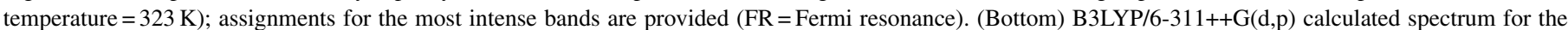

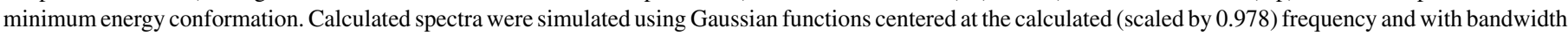
at half height equal to $5 \mathrm{~cm}^{-1}$. 
Among the most intense bands in the 5MPT spectrum, the doublet at $1512.5 / 1510.5 \mathrm{~cm}^{-1}(\delta \mathrm{C}-\mathrm{H}$ P-ring 2$)$, multiplet in the $1090-1070 \mathrm{~cm}^{-1}$ region ( $\nu \mathrm{C}-\mathrm{C}$ P-ring 6) and triplet at $758.5 / 756.5 / 754.9 \mathrm{~cm}^{-1}(\gamma \mathrm{C}-\mathrm{H}$ P-ring 1$)$ belong to the phenyl moiety (see Fig. 2 and Table 1). These modes occur at 1505.2, $1078.2 / 1074.3$ and $754.6 / 747.9 / 746.2 \mathrm{~cm}^{-1}$, respectively, for 1-phenyltetrazolone [19], at $1506.8,1077.3$ and $760.8 \mathrm{~cm}^{-1}$ for 5-chloro-1-phenyltetrazole [15] and 1511.8, 1089.5/1085.4 and $756.2 \mathrm{~cm}^{-1}$ for 1-phenyltetrazole [15]. All the remaining most intense bands in the IR spectrum of 5MPT are associated with modes originated in the tetrazole ring or methoxyl group and correspond to $\nu \mathrm{N}=\mathrm{C}, \nu \mathrm{C}-\mathrm{N}, \delta \mathrm{CH}_{3}$ symmetric, $\nu \mathrm{N}-\mathrm{N}$ and $\nu \mathrm{O}-\mathrm{C}$ vibrational modes (see Fig. 2 and Table 1). The $\nu \mathrm{N}=\mathrm{C}$ vibrational mode gives rise to the most intense band of the spectrum and occurs as a site split doublet at 1572.3 and $1571.3 \mathrm{~cm}^{-1}$. It represents ca. the fifth part of the total intensity of the spectrum $(18.4 \%$ of the experimental spectrum and $21.8 \%$ of the calculated spectrum). In 1-phenyltetrazole and 5chloro-1-phenyltetrazole [15] the equivalent vibrations absorb at $1474.6 / 1471.4$ and $1435.2 / 1429.5 \mathrm{~cm}^{-1}$, respectively, thus ca. $100 \mathrm{~cm}^{-1}$ below the observed frequency for 5MPT. However, the $\mathrm{N}_{4}=\mathrm{C}_{5}$ bond lengths are similar in all three compounds. Thus, the different observed frequencies reflect essentially the vibrational coupling, which is substantially different in 5MPT when compared with the other two compounds, and should not reflect any substantially different electronic characteristics (such as bond order) of the $\mathrm{N}_{4}=\mathrm{C}_{5}$ bond in the three compounds. Indeed, according to the calculations, in 5MPT the contribution of the $\nu \mathrm{C}-\mathrm{O}$ coordinate of the methoxyl substituent to this mode is very important ( $35.5 \%$; see Table S2), what by itself changes pronouncedly the nature of the vibration when compared with those of 1-phenyltetrazole and 5-chloro-1-phenyltetrazole [15].

$\nu \mathrm{C}-\mathrm{N}$ (associated with the $\mathrm{C}_{5}-\mathrm{N}_{1}$ bond) is observed at $1450.1 / 1448.0 \mathrm{~cm}^{-1}$ and is the third most intense band in the spectrum (see Table 1 and Fig. 2). It is quite coupled with the $\nu \mathrm{N}=\mathrm{C}$ coordinate (see Table S2), what justifies its relatively high frequency when compared, for instance, with that corresponding to the stretching mode of the $\mathrm{N}_{1}-\mathrm{C}_{6}$ inter-ring distance (observed as a multiplet in the $1300-1284 \mathrm{~cm}^{-1}$ region; Table 1). $v \mathrm{~N}-\mathrm{N}$ (associated with the $\mathrm{N}_{3}-\mathrm{N}_{4}$ bond) is observed at $1122.7 \mathrm{~cm}^{-1}$ and does also correspond to a considerably delocalized mode, whereas the $\delta \mathrm{CH}_{3}$ symmetric vibration is observed as a site split doublet at $1426.1 / 1424.8 \mathrm{~cm}^{-1}$, being, as expected, a well-localized vibration (see Table S2). Finally, $\nu \mathrm{O}-\mathrm{C}$ is the last vibration among the most intense bands of the tetrazole ring and methoxyl substituent mentioned above. It is a relatively welllocalized vibration and absorbs $\left(1014.2 / 1011.5 \mathrm{~cm}^{-1}\right)$ within the characteristic frequency range for this mode in methyl esters and methyl ethers (around 1050-950 $\mathrm{cm}^{-1}$ [49]).

Taking into consideration the good agreement between the experimental and calculated spectra (see Fig. 2), the assignment of the weaker bands in the observed spectrum could also be made in a straightforward way. A few weak bands that could not be assigned to fundamentals were also identified in the spectrum and tentatively ascribed to overtones or combination bands, as shown in Table 1.
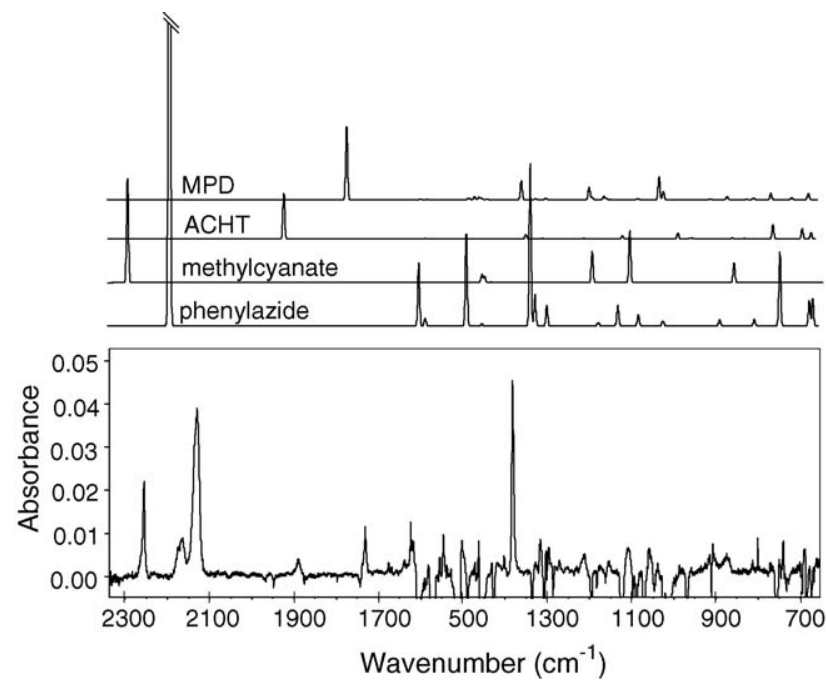

Fig. 3. (Bottom) Changes in infrared spectrum of 5-methoxy-1-phenyl- $1 H$ tetrazole trapped in an argon matrix induced by UV $(\lambda>235 \mathrm{~nm})$ irradiation (spectrum of UV-irradiated $(80 \mathrm{~min})$ sample - spectrum of freshly deposited matrix). (Upper traces) The B3LYP/6-311++G(d,p) calculated spectra of the observed photoproducts. The calculated bands were simulated using Gaussian functions centered at the scaled (by 0.978) frequency and with bandwidth at half height equal to $5 \mathrm{~cm}^{-1}$. In the theoretical spectra, intensities were scaled by different factors, in order to better simulate the experimental spectrum presented in the figure. The complete calculated spectra are provided as Supplementary Information (Tables S4-S7). MPD =3-methoxy-1-phenyl- $1 H$ diazirene; ACHT = 1-aza-1,2,4,6-cycloheptatetraene.

\section{3. $U V$-irradiation experiments $(\lambda>235 \mathrm{~nm})$}

Upon broadband UV-irradiation $(\lambda>235 \mathrm{~nm})$ of matrixisolated monomeric 5MPT the spectrum of the compound lost intensity, while new bands developed. The most prominent features of the photoproducts were observed in the $2300-1700 \mathrm{~cm}^{-1}$ spectral range, though other features could also be observed in the low frequency spectral region, including a relatively intense feature around $1380 \mathrm{~cm}^{-1}$ (Fig. 3). The complete list of bands due to the products of photolysis of 5MPT is presented in Table 2. The proposed reaction pathways are schematically shown in Fig. 4.

As it could be expected, comparatively to other previously studied tetrazoles [15-19] the observed photochemistry of 5MPT was considerably simpler. Essentially, two reaction pathways could be identified: (1) cleavage of the tetrazole ring through the $\mathrm{C}_{5}-\mathrm{N}_{1}$ and $\mathrm{N}_{3}-\mathrm{N}_{4}$ bonds, with production of phenylazide and methylcyanate as primary photoproducts (phenylazide can then undergo further reactions to give 1-aza1,2,4,6-cycloheptatetraene-ACHT) and (2) molecular nitrogen elimination, leading to formation of antiaromatic 3-methoxy1-phenyl-1H-diazirene (MPD). The first process is clearly the preferred reaction channel, as it can be noticed by comparing the relative intensities of the mark bands due to the different photoproducts, appearing in the $2300-1700 \mathrm{~cm}^{-1}$ spectral range.

Both observed photoprocesses imply cleavage of the $\mathrm{N}_{3}-\mathrm{N}_{4}$ bond. The first one also implies disruption of the $\mathrm{C}_{5}-\mathrm{N}_{1}$ bond, while the second one requires cleavage of the $\mathrm{N}_{1}-\mathrm{N}_{2}$ bond. According to the calculations, these are the three longest bonds 
Table 2

Experimental and calculated [B3LYP/6-311++G(d,p); scaled by 0.978] vibrational frequencies and calculated IR intensities for the observed photoproducts of 5-methoxy-1-phenyl-1 $H$-tetrazole isolated in solid argon ${ }^{\mathrm{a}}$

\begin{tabular}{|c|c|c|c|c|c|}
\hline \multirow[t]{2}{*}{ Approximate description $^{\mathrm{b}}$} & \multirow[t]{2}{*}{ Symmetry } & \multicolumn{2}{|l|}{ Calculated } & \multirow[t]{2}{*}{ Observed frequency $\left(\mathrm{cm}^{-1}\right)$} & \multirow[t]{2}{*}{ Literature frequency $\left(\mathrm{cm}^{-1}\right)$} \\
\hline & & Frequency $\left(\mathrm{cm}^{-1}\right)$ & Intensity $\left(\mathrm{km} \mathrm{mol}^{-1}\right)$ & & \\
\hline Methylcyanate & $C_{s}$ & & & & [48] (gas phase) \\
\hline$\delta \mathrm{CH}_{3}$ as.' & $\mathrm{A}^{\prime}$ & 1461.4 & 16.4 & 1462.1 & 1470 \\
\hline$\delta \mathrm{CH}_{3}$ as. $^{\prime \prime}$ & $\mathrm{A}^{\prime \prime}$ & 1455.1 & 12.2 & 1453.4 & 1462 \\
\hline$\gamma \mathrm{CH}_{3}{ }^{\prime}$ & $\mathrm{A}^{\prime}$ & 1200.1 & 62.1 & 1215.3 & 1213 \\
\hline \multirow{3}{*}{$\begin{array}{l}\text { Phenylazide } \\
\qquad v \mathrm{~N}=\mathrm{N}=\mathrm{N} \text { as. }\end{array}$} & $C_{\mathrm{s}}$ & & & & {$[50]\left(\mathrm{N}_{2}\right.$ matrix $)$} \\
\hline & $\mathrm{A}^{\prime}$ & 2191.4 & 843.5 & $2174.6 / 2164.7$ & $2165 / 2157 / 2137 / 2128^{c}$ \\
\hline & & & & $2134.3 / 2129.6$ & $2112 / 2102 / 2087$ \\
\hline$v(\mathrm{C}-\mathrm{C}$ ring 2$)$ & $\mathrm{A}^{\prime}$ & 1600.5 & 59.2 & 1618.4 & 1598 \\
\hline$v(\mathrm{C}-\mathrm{C}$ ring 4$)$ & $\mathrm{A}^{\prime}$ & 1585.3 & 6.4 & 1581.3 & $1589 / 1585$ \\
\hline$\delta(\mathrm{C}-\mathrm{H}$ ring 2$)$ & $\mathrm{A}^{\prime}$ & 1487.7 & 86.3 & 1502.8 & $1496 / 1491$ \\
\hline$v \mathrm{~N}-\mathrm{C}$ & $\mathrm{A}^{\prime}$ & 1128.9 & 18.3 & $\sim 1125^{\mathrm{d}}$ & $1136 / 1131$ \\
\hline$v(\mathrm{C}-\mathrm{C}$ ring 5$)$ & $\mathrm{A}^{\prime}$ & 1022.0 & 4.4 & 1039.0 & 1026 \\
\hline$\gamma(\mathrm{C}-\mathrm{H}$ ring 3$)$ & $\mathrm{A}^{\prime \prime}$ & 887.7 & 5.2 & 908.4 & 896 \\
\hline$\delta \mathrm{CNN}$ & $\mathrm{A}^{\prime}$ & 805.5 & 5.3 & 813.3 & 810 \\
\hline$\gamma(\mathrm{C}-\mathrm{H}$ ring 1$)$ & $\mathrm{A}^{\prime \prime}$ & 744.9 & 68.7 & 740.4 & 751 \\
\hline$\tau($ ring 1$)$ & $\mathrm{A}^{\prime \prime}$ & 675.2 & 23.2 & 662.1 & 687 \\
\hline$\delta \mathrm{NNN}$ & $\mathrm{A}^{\prime}$ & 666.9 & 25.1 & 655.3 & 670 \\
\hline \multirow{5}{*}{$\begin{array}{l}\mathrm{ACHT} \\
\qquad \mathrm{C}=\mathrm{C}=\mathrm{Na} \\
\delta(\mathrm{C}-\mathrm{H} 1) \\
\delta(\mathrm{C}-\mathrm{H} 2) \\
\nu \mathrm{N}-\mathrm{C} \\
\gamma(\mathrm{C}-\mathrm{H} 1) \\
\gamma(\mathrm{C}-\mathrm{H} 2) \\
\gamma(\mathrm{C}-\mathrm{H} 3) \\
\delta \mathrm{CCN} \\
\tau(\text { ring } 1) \\
\gamma \mathrm{CCN}\end{array}$} & $C_{1}$ & & & & [49] (Ar matrix) \\
\hline & & 1913.1 & 202.2 & 1891.5 & 1895 \\
\hline & & 1201.8 & 3.9 & $1215.3^{\mathrm{e}}$ & \\
\hline & & 1110.9 & 15.2 & $1107.2^{\mathrm{e}}$ & 1111 \\
\hline & & 979.7 & 25.6 & 986.7 & 980 \\
\hline$\delta \mathrm{CH}_{3}$ as.' & & 1465.7 & 17.7 & 1471.2 & \\
\hline$\delta \mathrm{CH}_{3}$ as." & & 1454.8 & 14.1 & $1462.1^{\mathrm{e}}$ & \\
\hline$\delta(\mathrm{C}-\mathrm{H}$ ring 2$)$ & & 1449.0 & 7.8 & 1458.1 & \\
\hline$v \mathrm{C}-\mathrm{N}$ & & 1354.8 & 111.8 & 1402.3 & \\
\hline$\delta(\mathrm{C}-\mathrm{H}$ ring 1$)$ & & 1297.0 & 6.8 & 1271.1 & \\
\hline$v \mathrm{~N}-\mathrm{C}$ & & 1194.3 & 72.5 & $1215.3^{\mathrm{e}}$ & \\
\hline$\gamma \mathrm{CH}_{3}^{\prime}$ & & 1187.4 & 13.7 & & \\
\hline$\delta(\mathrm{C}-\mathrm{H} \operatorname{ring} 4)$ & & 1159.4 & 18.3 & 1155.0 & \\
\hline$\delta(\mathrm{C}-\mathrm{H}$ ring 5$)$ & & 1154.0 & 7.6 & & \\
\hline$\nu \mathrm{O}-\mathrm{C}\left(\mathrm{H}_{3}\right)$ & & 1028.5 & 133.4 & 1057.9 & \\
\hline$v(\mathrm{C}-\mathrm{C}$ ring 5$)$ & & 1018.3 & 47.2 & $1039.0^{\mathrm{f}}$ & \\
\hline$\gamma(\mathrm{C}-\mathrm{H}$ ring 3$)$ & & 908.1 & 2.8 & $914.8(?)$ & \\
\hline$\nu \mathrm{C}-\mathrm{O}$ & & 867.6 & 18.0 & $874.0^{\mathrm{e}}$ & \\
\hline$\gamma(\mathrm{NN}(\mathrm{C}) \mathrm{O})^{\mathrm{g}}$ & & 804.6 & 9.4 & 801.1 & \\
\hline$\gamma(\mathrm{C}-\mathrm{H}$ ring 1$)$ & & 763.6 & 36.1 & $\sim 754^{\mathrm{d}}$ & \\
\hline$\tau($ ring 1$)$ & & 675.0 & 36.5 & $\sim 685^{\mathrm{d}}$ & \\
\hline
\end{tabular}

${ }^{\text {a }}$ Complete calculated spectra are presented in Tables S4-S7 (Supplementary Information).

b $\nu$, stretching; $\delta$, bending; $\gamma$, rocking; $\tau$, torsion; ring modes were given the names in consonance with those used for 5MPT.

c Shoulder.

d Overlapped with a band of the reactant (5MPT).

e Overlapped with a band of methylcyanate.

${ }^{\mathrm{f}}$ Overlapped with a band of phenylazide.

g $\mathrm{C}$ out of the $\mathrm{N}-\mathrm{N}-(\mathrm{C})-\mathrm{O}$ plane bending vibration. 


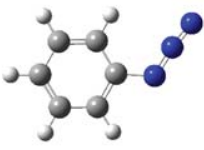

phenylazide
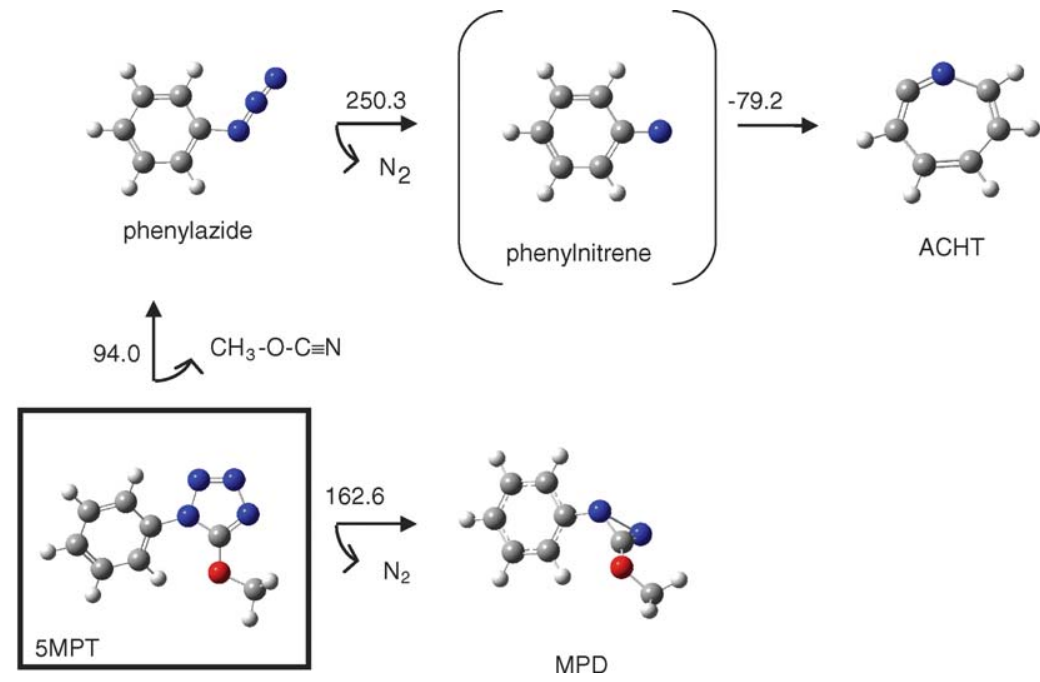

Fig. 4. Proposed pathways resulting from irradiation of 5-methoxy-1-phenyl- $1 \mathrm{H}$-tetrazole in an argon matrix through the outer $\mathrm{KBr}$ window of the cryostat $(\lambda>235 \mathrm{~nm})$. Reaction energies (with zero point corrections) are in $\mathrm{kJ} \mathrm{mol}^{-1}$.

in the tetrazole ring (with calculated lengths longer than 135.5 pm; see Table S1). The $\mathrm{N}_{2}=\mathrm{N}_{3}$ and $\mathrm{C}_{5}=\mathrm{N}_{4}$ bonds are considerably shorter (128.0 and $131.3 \mathrm{pm}$, respectively, as calculated at the DFT(B3LYP)/6-311++G(d,p) level of theory). Hence, the bonds that are directly involved in the reactions correspond to the weaker bonds. Moreover, for this molecule, both the HOMO and the LUMO are of $\pi$-character (Fig. 5). According to the calculations, the vertical $\pi^{*} \leftarrow \pi$ excitation corresponding to a single excitation from the HOMO to the LUMO (roughly estimated from the LUMO - HOMO energy difference) has a wavelength of ca. $220 \mathrm{~nm}$, which doubtlessly indicates that this corresponds to the reactive excitation. Very interestingly, contrarily to the HOMO orbital, which has a bonding character on the $\mathrm{C}_{5}-\mathrm{N}_{1}$ bond, the LUMO is anti-bonding on this bond, thus explaining why it is so easy to break this bond upon photochemical excitation at $\lambda>235 \mathrm{~nm}$. Note that the LUMO orbital does also have an anti-bonding character on the $\mathrm{N}_{1}-\mathrm{N}_{2}$ bond, which is cleaved in the alternative reaction path instead of $\mathrm{C}_{5}-\mathrm{N}_{1}$ (see Fig. 5). The preference for the reaction path leading to phenylazide and methylcyanate, when compared with that leading to molecular nitrogen plus MPD, is in consonance with the reaction energies (94.0 and $162.6 \mathrm{~kJ} \mathrm{~mol}^{-1}$, respectively; see Fig. 4), which clearly favor the first process relatively to the second one.

All strong and medium intensity bands predicted for the two major products formed in Pathway 1 (phenylazide and methylcyanate) could be observed in the spectra of the irradiated matrix (see Fig. 3 and Table 2). Methylcyanate is a quite unstable compound under normal experimental conditions and in particular in solid phase, isomerizing quickly to its more stable isomer methylisocyanate [50-53] (the DFT(B3LYP)/6-311++G(d,p) calculated energy of methylisocyanate is $127.5 \mathrm{~kJ} \mathrm{~mol}^{-1}$ lower than that of methylcyanate). Its synthesis was first reported in 1965, by two different groups [50,51], although a pure sample could not be obtained for spectroscopic investigation because of the instability of the molecule. This was only achieved much later, when Pasinszki and Westwood [52] reported the midinfrared spectrum of gaseous methylcyanate. All vibrations of methylcyanate absorbing above $650 \mathrm{~cm}^{-1}$, except the $\delta \mathrm{CH}_{3}$ symmetric bending mode (calculated intensity: $0.9 \mathrm{~km} \mathrm{~mol}^{-1}$; see Table S4), could be identified in the observed spectrum and
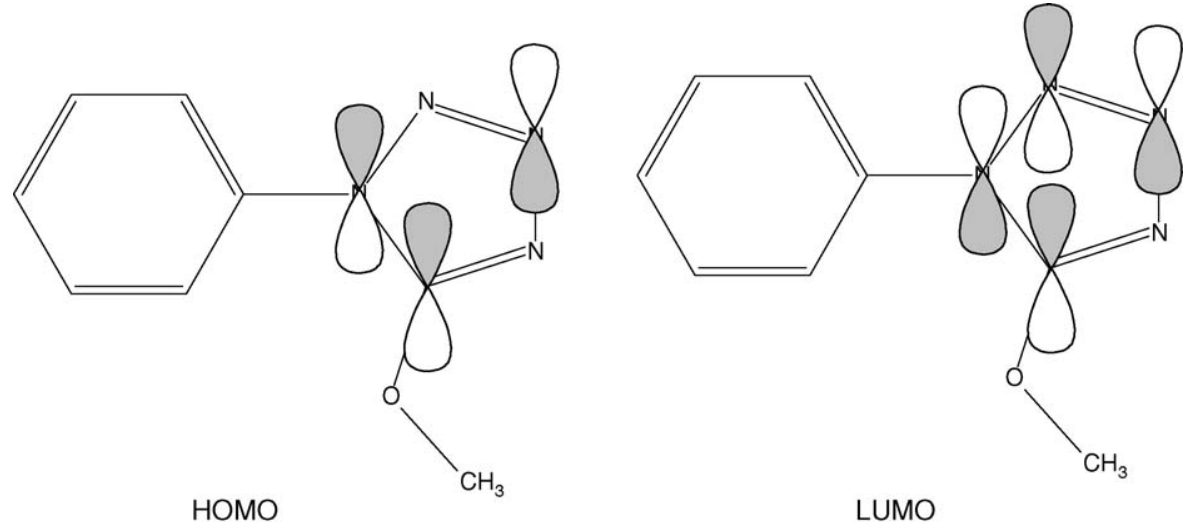

LUMO

Fig. 5. Schematic representation of the HOMO and LUMO of 5-methoxy-1-phenyl-1H-tetrazole. Heavy atoms from the phenyl ring also significantly contribute to both orbitals, but this figure aims only to describe the format of the orbitals in the tetrazole ring. The global pictures of the two orbitals are given in Figure S1 (Supplementary Information). 
duly assigned [52]. In the present study, all bands reported for the gas phase could also be observed in the spectra of the irradiated matrix (Table 2), with the only exception of the very weak band due to $\gamma \mathrm{CH}_{3}$ " mode (appearing at $1199 \mathrm{~cm}^{-1}$ in the gas phase [52]; calculated intensity: $0.6 \mathrm{~km} \mathrm{~mol}^{-1}$; Table S4), unequivocally testifying for the presence of this species in the matrix. Very interestingly, no evidence of isomerization of methylcyanate to methylisocyanate was found, indicating that under the experimental conditions used, methylcyanate is stable in relation to the isomerization to the isocyanate.

Phenylazide is produced in Pathway 1 together with methylcyanate (Fig. 4). This compound has been previously isolated and irradiated in both argon and nitrogen matrices, and production of 1-aza-1,2,4,6-cycloheptatetraene (ACHT) unequivocally demonstrated [19,54-56]. The vibrational spectra of matrixisolated phenylazide and of ACHT are then well known and their identification could be made here without any difficulty (see Table 2).

As found in our previous study on 1-phenyltetrazolone [19], under the experimental conditions used phenylazide reacts with relatively low efficiency, in particular when compared to the reactions undergone by the tetrazole compounds. The intermediate for this reaction is, with all probability, singlet phenylnitrene, which has been found to easily undergo ring expansion to ACHT (the calculated ground state energies for these two species favor the latter compound by ca. $80 \mathrm{~kJ} \mathrm{~mol}^{-1}$, see Fig. 4). Characteristic bands of ACHT [19,57-59] could be clearly identified in the spectra of the irradiated matrix. Particularly noticeable is the band-mark associated with the intense antisymmetric stretching vibration of the ketenimine moiety $(\nu \mathrm{C}=\mathrm{C}=\mathrm{N}$ as.) of ACHT, observed at $1891.5 \mathrm{~cm}^{-1}$ (Fig. 3). Other bands previously described by Chapman and Le Roux [54] as well as by Huisgen and Vossius [58] as fingerprints of this compound could also be clearly identified in the spectra (Table 2). Note also that as previously found for UV-irradiated 1-phenyltetrazolone monomer isolated in argon [19], triplet phenylnitrene (reported to be present in low temperature matrices as a result of direct photolysis of isolated phenylazide [56]) was not observed in the present study, even when irradiation was undertaken using different wavelength cut-off filters (e.g., 285, 337, 375 and $417 \mathrm{~nm}$ ). Like previously suggested [19], the absence of observation of triplet phenylnitrene may result from the fact that phenylazide is produced together with other species and might interact in the matrix cage, eventually making inaccessible the pathway which would lead to formation of the triplet nitrene.

Pathway 2 involves the loss of molecular nitrogen to produce 3-methoxy-1-phenyl-1H-diazirene (MPD; Fig. 4), which was now observed for the first time. The ejection of molecular nitrogen after irradiation of tetrazole compounds to give diazirenes has already been described [15,19]. Diazirenes can be easily identified because their most intense band $(\nu \mathrm{C}=\mathrm{N}$; see Table 2 and Table S6) occurs in a "clean" region of the spectrum $\left(1850-1720 \mathrm{~cm}^{-1}\right)$ and can be considered as fingerprint of this family of compounds. Only one conformer was located on the potential energy surface of MPD. Hence, the structure observed in the feature assigned to this compound at around $1735 \mathrm{~cm}^{-1}$ should be attributed to matrix site splitting. On the whole, MPD has 51 infrared vibrations. However, in the studied region (between 2300 and ca. $600 \mathrm{~cm}^{-1}$ ) the calculations predict only 17 modes with intensities larger than $6 \mathrm{~km} \mathrm{~mol}^{-1}$ (see Table S6). From them, 16 could be assigned to bands observed in the spectra of the irradiated matrix (Table 2).

\section{Conclusion}

In this work, monomeric 5MPT was isolated in solid argon and its infrared spectrum fully assigned. In situ UV-irradiation $(\lambda>235 \mathrm{~nm})$ of the matrix led to the production of methylcyanate and phenylazide, in one reaction channel, and also of the antiaromatic MPD, in the other. The primarily formed phenylazide partially converted to ACHT, with all probability involving singlet phenylnitrene as intermediate. The identification of all the photoproducts as well as the interpretation of the spectrum of the isolated 5MPT were supported by extensive DFT calculations and, whenever available, by previously reported data on these compounds as matrix-isolated species or in the gaseous phase [15,19,52-54].

The relatively simple photochemistry of 5MPT, when compared with previously studied tetrazoles [14-19,55], was attributed to two main facts: (a) it has only one stable conformation and (b) does not have labile hydrogen atoms directly bound to the tetrazole ring or in the tetrazole substituents. This relative simplicity allowed attaining a high degree of certainty in the identification and characterization of the different photoproducts and shed light on important details of the photochemistry of tetrazoles.

\section{Acknowledgements}

The authors acknowledge the Portuguese Science Foundation (FCT_POCTI/QUI/59019/2004 and POCTI/QUI/58937/ 2004), FEDER, Instituto de Investigação Interdisciplinar (Project III/Bio/40/2005) and the Argentinian Agencia Nacional de Promoción Científica y Tecnológica (PICT 13080) for financial support. A.G.-Z. thanks FCT (Grant SFRH/BPD/11499/ 2002). I.D.R. acknowledges FCT for the Grant SFRH/BPD/ 1661/2000. L.M.T.F. acknowledges FCT for the Grant SFRH/ BD/17945/2004.

\section{Appendix A. Supplementary data}

Supplementary data associated with this article can be found, in the online version, at doi:10.1016/j.jphotochem.2005.10.012.

\section{References}

[1] T. Mavromoustakos, A. Kolocouris, M. Zervou, P. Roumelioti, J. Matsoukas, R. Weisemann, J. Med. Chem. 42 (1999) 1714.

[2] J.H. Toney, P.M.D. Fitzgerald, N. Groversharma, S.H. Olson, W.J. May, J.G. Sundelof, D.E. Vanderwall, K.A. Cleary, S.K. Grant, J.K. Wu, J.W. Kozarich, D.L. Pompliano, G.G. Hammond, Chem. Biol. 5 (1998) 185.

[3] Y. Hashimoto, R. Ohashi, Y. Kurosawa, K. Minami, H. Kaji, K. Hayashida, H. Narita, S. Murata, J. Cardiovasc. Pharm. 31 (1998) 568.

[4] A. Desarro, D. Ammendola, M. Zappala, S. Grasso, G.B. Desarro, Antimicrob. Agents Chemother. 39 (1995) 232. 
[5] Y. Tamura, F. Watanabe, T. Nakatani, K. Yasui, M. Fuji, T. Komurasaki, H. Tsuzuki, R. Maekawa, T. Yoshioka, K. Kawada, K. Sugita, M. Ohtani, J. Med. Chem. 41 (1998) 640.

[6] A.D. Abell, G.J. Foulds, J. Chem. Soc., Perkin Trans. 1 (17) (1997) 2475.

[7] G. Sandmann, C. Schneider, P. Boger, Z. Naturforsch. C 51 (1996) 534.

[8] H. Singh, A.S. Chawla, V.K. Kapoor, D. Paul, R.K. Malhotra, Prog. Med. Chem. 17 (1980) 151.

[9] K. Noda, Y. Saad, A. Kinoshita, T.P. Boyle, R.M. Graham, A. Husain, S.S. Karnik, J. Biol. Chem. 270 (1995) 2284.

[10] G.G. Smirnova, O.P. Kovaleva, T.V. Artamova, A.P. Koreneva, G.I. Koldobskii, Russ. J. Org. Chem. 39 (2003) 1679.

[11] Z.P. Demko, K.B. Sharpless, Angew. Chem. Int. Ed. 41 (2002) 2110, and references cited therein.

[12] A. Vollmar, A. Hassner, J. Heterocycl. Chem. 11 (1974) 491.

[13] M.L.S. Cristiano, PhD Thesis, University of Liverpool, 1994.

[14] S.C.S. Bugalho, E.M.S. Maçôas, M.L.S. Cristiano, R. Fausto, Phys. Chem. Chem. Phys. 3 (2001) 3541.

[15] S.C.S. Bugalho, L. Lapinski, M.L.S. Cristiano, L.M.T. Frija, R. Fausto, Vib. Spectrosc. 30 (2002) 213.

[16] S.C.S. Bugalho, A.C. Serra, L. Lapinski, M.L. Cristiano, R. Fausto, Phys. Chem. Chem. Phys. 4 (2002) 1725.

[17] A. Gómez-Zavaglia, I.D. Reva, L. Frija, M.L. Cristiano, R. Fausto, J. Phys. Chem. A 109 (2005) 7967.

[18] A. Gómez-Zavaglia, I.D. Reva, L. Frija, M.L. Cristiano, R. Fausto, J. Mol. Struct., doi:10.1016/j.molstruc.2005.08.019.

[19] A. Gómez-Zavaglia, I.D. Reva, L. Frija, M.L. Cristiano, R. Fausto, J. Photochem. Photobiol. A 179 (2006) 243-255.

[20] G. Maier, J. Eckwert, A. Bothur, H.P. Reisenauer, C. Schmidt, Leibigs Ann. (1996) 1041.

[21] I.R. Dunkin, C.J. Shields, H. Quast, Tetrahedron 45 (1989) 259.

[22] Y.B. Chae, K.S. Chang, S.S. Kim, The Daehan Hwak Hwoejee 11 (1967) 85.

[23] A. Awadallah, K. Kowski, P. Rademacher, J. Heterocycl. Chem. 34 (1997) 113.

[24] M.L.S. Cristiano, R.A.W. Johnstone, J. Chem. Res. (Synopses) 5 (1997) 164.

[25] M.L.S. Cristiano, R.A.W. Johnstone, J. Chem. Soc., Perkin 2 (1997) 489.

[26] I.D. Reva, S. Stepanian, L. Adamowicz, R. Fausto, J. Phys. Chem. A 105 (2001) 4773.

[27] M. Frisch, G. Trucks, H. Schlegel, G. Scuseria, M. Robb, J. Cheeseman, V. Zakrzewski, J. Montgomery, R. Stratmann, K. Burant, S. Dapprich, J. Millam, A. Daniels, K. Kudin, M. Strain, O. Farkas, J. Tomasi, V. Barone, M. Cossi, R. Cammi, B. Mennucci, C. Pomelli, C. Adamo, S. Clifford, J. Ochterski, G. Petersson, P. Ayala, Q. Cui, K. Morokuma, D. Malick, A. Rabuck, K. Raghavachari, J. Foresman, J. Cioslowski, J. Ortiz, A. Baboul, B. Stefanov, G. Liu, A. Liashenko, P. Piskorz, I. Komaromi, R. Gomperts, R. Martin, D. Fox, T. Keith, M. Al-Laham, C.
Peng, A. Nanayakkara, M. Challacombe, P. Gill, B. Johnson, W. Chen, M. Wong, J. Andres, C. Gonzalez, M. Head-Gordon, S. Replogle, J. Pople, Gaussian98, Revision A.9, Gaussian Inc., Pittsburgh, PA, 1998. [28] A.D. Becke, Phys. Rev. A 38 (1988) 3098.

[29] C.T. Lee, W.T. Yang, R.G. Parr, Phys. Rev. B 37 (1988) 785.

[30] P. Csaszar, P. Pulay, J. Mol. Struct. (Theochem.) 114 (1984) 31.

[31] J.H. Schachtschneider, Technical Report, Shell Development Co., Emeryville, CA, 1969.

[32] A. Hargreaves, S.H. Rizvi, Acta Crystallogr. 15 (1962) 365.

[33] H. Suzuki, Bull. Chem. Soc. Jpn. 32 (1959) 1340.

[34] G.H. Beaven, in: G.W. Gray (Ed.), Steric Effects in Conjugated Systems, Butterworths, London, 1958.

[35] M.A.V. Ribeiro da Silva, M.A.R. Matos, C.A. Rio, V.M.F. Morais, J. Wang, G. Nichols, J.S. Chickos, J. Phys. Chem. A 104 (2000) 1774.

[36] J. Catalán, J.L.G. de Paz, J.C. Del Valle, M. Kasha, J. Phys. Chem. A 101 (1997) 5284.

[37] D.E. Lynch, I. McClenaghan, Acta Crystallogr. E 57 (2001) 264.

[38] N.H. Damrauer, J.K. McCusker, J. Phys. Chem. A 103 (1999) 8440.

[39] M.K. Cyranski, J. Mieczkowski, Acta Crystallogr. C 54 (1998) 1521.

[40] T. Matsunaga, Y. Ohno, Y. Akutsu, M. Arai, M. Tamura, M. Iida, Acta Crystallogr. C 55 (1999) 129.

[41] J. Zucherman-Schpector, E.J. Barreiro, A.C.C. Freitas, Acta Crystallogr. C 50 (1994) 2095.

[42] A. Kowalski, Acta Crystallogr. C 51 (1995) 1670.

[43] N.H. Damrauer, B.T. Weldon, J.K. McCusker, J. Phys. Chem. A 102 (1998) 3382.

[44] L.A.E. Batista de Carvalho, J.J.C. Teixeira-Dias, R. Fausto, Struct. Chem. 1 (1990) 533.

[45] R. Pearson, F. Lovas, J. Chem. Phys. 66 (1977) 4149.

[46] S. Cradock, C. Purves, D.W.H. Rankin, J. Mol. Struct. 220 (1990) 193.

[47] L. Fernholt, C. Römming, Acta Chem. Scand. A 32 (1978) 271.

[48] B.J.M. Bormans, G. de With, F.C. Mijlhoff, J. Mol. Struct. 42 (1977) 121.

[49] J.J.C. Teixeira-Dias, R. Fausto, J. Mol. Struct. 144 (1986) 199, and references therein.

[50] K.A. Jensen, M. Due, A. Holm, Acta Chem. Scand. 19 (1965) 438.

[51] D. Martin, W. Mucke, Chem. Ber. 98 (1965) 2063.

[52] T. Pasinszki, N.P.C. Westwood, J. Phys. Chem. 99 (1995) 1649.

[53] V.I. Faustov, E.G. Baskir, A.A. Biryukov, Russ. Chem. Bull., Intl. Ed. 52 (2003) 2328 (published also in Russian in Izv. Akad. Nauk., Ser. Kimicheskaya 11 (2003) 2203).

[54] O.L. Chapman, J.-P. Le Roux, J. Am. Chem. Soc. 100 (1978) 282.

[55] I. Dunkin, Spectrochim. Acta 42 (1986) 649.

[56] J.C. Hayes, R.S. Sheridan, J. Am. Chem. Soc. 112 (1990) 5879.

[57] S. Otsuka, A. Nakamura, T.J. Yoshida, Organometall. Chem. 7 (1967) 339.

[58] R. Huisgen, D. Vossius, M. Appl, Chem. Ber. 91 (1958) 1; R. Huisgen, D. Vossius, M. Appl, Chem. Ber. 91 (1958) 12. 